\title{
AVALIAÇÃo dA BIOdEGRADABILIDADE ANAERÓBIA DE LIXIVIADOS DE ATERRO SANITÁRIOS
}

\author{
EVALUATE OF THE ANAEROBIC BIODEGRADABILITY OF LANDFILL LEACHATE
}

\section{MírIam CRISTINa SANTOS AMARAL}

Engenheira Química, Mestranda em Saneamento, Meio Ambiente e Recursos Hídricos no Departamento de Engenharia Sanitária e Ambiental da Universidade Federal de Minas Gerais (UFMG)

\section{CYNTHIA FANTONI ALVES FERREIRA}

Engenheira Civil, Especialista em Gestão Ambiental, Mestre em Saneamento, Meio Ambiente e Recursos Hídricos pela Universidade Federal de Minas Gerais (UFMG), e doutoranda em Saneamento, Meio Ambiente e Recursos Hídricos no Departamento de Engenharia Sanitária e Ambiental da Universidade Federal de Minas Gerais (UFMG)l

\section{LISÉTE CELINA LANGE}

Química, Doutora em Tecnologia Ambiental pela Universidade de Londres - Inglaterra, Profa . Adjunta do Departamento de Engenharia Sanitária e Ambiental da Universidade Federal de Minas Gerais (UFMG)1

\section{SÉRGIO FRANCISCO DE AQUINO}

Químico, Doutor em Engenharia Química pela Universidade de Londres - Inglaterra. Prof. Adjunto do Departamento de Química da Universidade Federal de Ouro Preto (UFOP)

Recebido: 26/04/07 Aceito: 13/11/07

\begin{abstract}
RESUMO
Os objetivos deste artigo foram investigar as condições ambientais e operacionais favoráveis ao desenvolvimento do teste de biodegradabilidade anaeróbia para lixiviados de aterro sanitário. As condições avaliadas foram a relação alimento/microrganismo (A/M), aclimatação do lodo, e toxicidade devido à alta concentração de amônia. Os resultados indicaram que a relação $\mathrm{A} / \mathrm{M}$ equivalente a 0,45 apresentou-se como a mais favorável à realização do teste, e que o lodo empregado apresentou boa capacidade de adaptação ao lixiviado, não demandando aclimatação prévia. O lixiviado em questão apresentou relativamente baixa biodegradabilidade anaeróbia, associado aos resultados de estudos de biodegradabilidade aeróbia anteriores que sugerem que uma significativa fração de matéria orgânica é refratária mesmo ao metabolismo aeróbio,indica que o tratamento físico-químico deve ser utilizado como forma de pré ou pós-tratamento.
\end{abstract}

PALAVRAS-CHAVE: Lixiviado, biodegradabilidade anaeróbia, produção acumulada de metano.

\section{ABSTRACT}

The objectives of this article were to investigate the favorable environment and operational conditions to the development of the anaerobic biodegradability test for landfill leachate. The evaluated conditions were the relation food/microrganismo $(A / M)$, seed acclimatization, and toxicity due to high ammonia concentration. The results indicated that $A / M$ relation equivalent to 0,45 was presented as most favorable to the accomplishment of the test, and that the seed used presented good capacity of adaptation to the leachate, not demanding previous acclimatization. The leachate in question presented relatively low anaerobic biodegradability, and associated to the results of previous studies of aerobic biodegradability suggest that a significant fraction of organic substance is refractory to the aerobic and anaerobic metabolism, indicating that the physical-chemical treatment must be used as form of pre or post-treatment.

KEYWORDS: Landfill leachate, biodegradability, biochemical methane potential (BMP).

\section{INTRODUÇÃO}

A geração de lixiviados constitui a principal preocupação quanto à degradação ambiental de áreas localizadas próximas ao local de disposição final dos resíduos sólidos urbanos (RSU), uma vez que o tratamento desses efluentes tem se mostrado um grande desafio. As tecnologias de tratamento anaeró-bio estão sendo cada vez mais usadas, devido as inerentes vantagens apresentadas em relação ao tratamento bioló-gico aeróbio, tais quais: menor geração de biomassa, conservação de energia e produção de metano, e menores requerimentos de área e nutrientes (Speece, 1996). No entanto, os processos anaeróbios apresentam maior sensibilidade às mudanças das condições ambientais e operacionais dos reatores, sendo por isso considerados mais instáveis que os processos aeróbios.
Uma forma de controlar os problemas inerentes aos processos anaeróbios é o emprego de caracterização mais detalhada do efluente antes, durante e após tratamento permitindo o entendimento de todo o processo. A caracterização baseada em parâmetros coletivos, como biodegradabilidade, apresenta grande importância por fornecer mais informaçôes práticas sobre a eficiência do sistema de tratamento, uma vez que pode ser 
empregada para analisar a concentração de poluentes orgânicos que podem ser convertidos a metano, bem como avaliar a eficiência e estimar a quantidade de poluentes orgânicos residuais do processo (Barker et al,1999 e Speece, 1996).

Uma substância ou composto é biodegradável quando for susceptível à decomposição pela ação dos microrganismos. Os microrganismos podem usar estes compostos como fonte de energia ou de carbono (Angelidaki et al, 2004). Neste contexto, a biodegradabilidade anaeróbia pode ser definida como a fração máxima de matéria orgânica que será eliminada, por digestão anaeróbia, durante um determinado período de tempo e em determinadas condições operacionais, em comparação à fração teórica estequiometricamente convertida (Field, et al, 1988 e Rozzi et al, 2004).

$\mathrm{Na}$ literatura são apresentados diversos métodos para determinação da biodegradabilidade de diversos efluentes ou lodo (Muller et al, 2004). Os testes de biodegradabilidade anaeróbia são baseados no monitoramento da formação de um ou mais produtos envolvidos na reação biológica, como por exemplo, o teste denominado Biochemical Methane Potential (BMP) que se baseia na medição da produção acumulada de metano (Owen et al, 1978), ou no monitoramento da depleção do substrato (Guwy, 2004). $\mathrm{Na}$ figura 1 é apresentado um esquema que ilustra os diferentes procedimentos para se determinar a biodegradabilidade de uma amostra sob condições anaeróbias.

Os métodos baseados no monitoramento dos produtos formados geralmente empregam simples aparatos para quantificar a quantidade de biogás, ou mesmo dos produtos intermediários (ácidos graxos voláteis) que se acumulam no meio em função da degradação do substrato a ser avaliado. A maioria dos testes emprega o monitoramento da produção de metano. A produção do biogás pode ser determinada pelo aumento do volume sob pressão constante (método volumétrico), ou pelo aumento da pressão a volume constante (método manométrico), e a concentração de metano no biogás é geralmente determinada por cromatografia (Guwy, 2004 e Rozzi et al, 2004). As técnicas para quantificar a taxa e volume da produção de biogás incluem seringas esmeriladas, manômetros, manômetros com seringas, ou medidores de fluxo a baixa pressão. A cromatografia gasosa é usada para determinar a quantidade de metano e dióxido de carbono do biogás acumulado no headspace dos frascos (Dolfing et al, 1985).

Os métodos baseados na depleção do substrato requerem o emprego de análises mais complexas. Tais análises podem ser agrupadas em técnicas que empregam parâmetros não-específicos, tais como demanda química de oxigênio (DQO) e carbono orgânico total (COT), ou aqueles que envolvem a quantificação de compostos específicos produzidos ou consumidos empregando-se cromatografia gasosa (CG), cromatografia líquida de alta eficiência (HPLC ou CLAE), cromatografia gasosa aclopada a espectrometria de massas (CG - EM) ou cromatografia líquida acoplada à espectrometria de massas (CL - EM).

Tanto para os métodos baseados na formação de produtos quanto na depleção do substrato são relatados alguns problemas com equipamentos e metodologias empregadas, tais como fenômenos de permeação, reprodutibilidade e composição da solução de nutriente (Angelidaki et al, 2004, Guwy,
2004, Muller et al, 2004 e Rozzi et al, 2004). Outro fator que pode também afetar a reprodutibilidade dos testes é a falta da padronização das condições ambientais e operacionais. Dentre estas condições destacam-se a relação substrato/microrganismo $(\mathrm{A} / \mathrm{M}), \mathrm{pH}$, solução de nutrientes, e temperatura. Associado a estes, existem ainda aqueles fatores que dificultam a interpretação dos resultados, tais como, forma de caracterizar o lodo (quantificação em volume, massa ou atividade metanogênica) e a presença de toxicidade na amostra que pode causar pseudo-biodegradabilidade, ou seja, a biodegradabilidade é baixa não devido à ausência de arsenal enzimático para degradar o material orgânico presente no efluente, e sim à presença de compostos tóxicos.

A digestão anaeróbia é um processo complexo que requer a presença de diversos microrganismos. Neste contexto é importante encontrar um inóculo apropriado que contenha os microrganismos necessários para o processo de degradação. Owen et al (1979) sugeriram o emprego de lodo de sistemas de tratamento de esgoto como inóculo. No entanto, muitas vezes o efluente é constituído de compostos que requerem enzimas adicionais, metabolismos ou condições ambientais não encontrados na fase de crescimento em que se encontram os microrganismos que compõe a biomassa, ou até mesmo contém compostos que em certas concentrações podem ser tóxicos à biomassa, estimulando o seu decaimento e lise. A amônia, quando em altas concentrações, é um dos compostos tóxicos mais comuns responsáveis pelos problemas operacionais durante o tratamento anaeróbio (Calli et al, 2005), e uma forma de contornar tais problemas é empregar a aclimatação da biomassa (Speece, 1996). O ideal seria o emprego

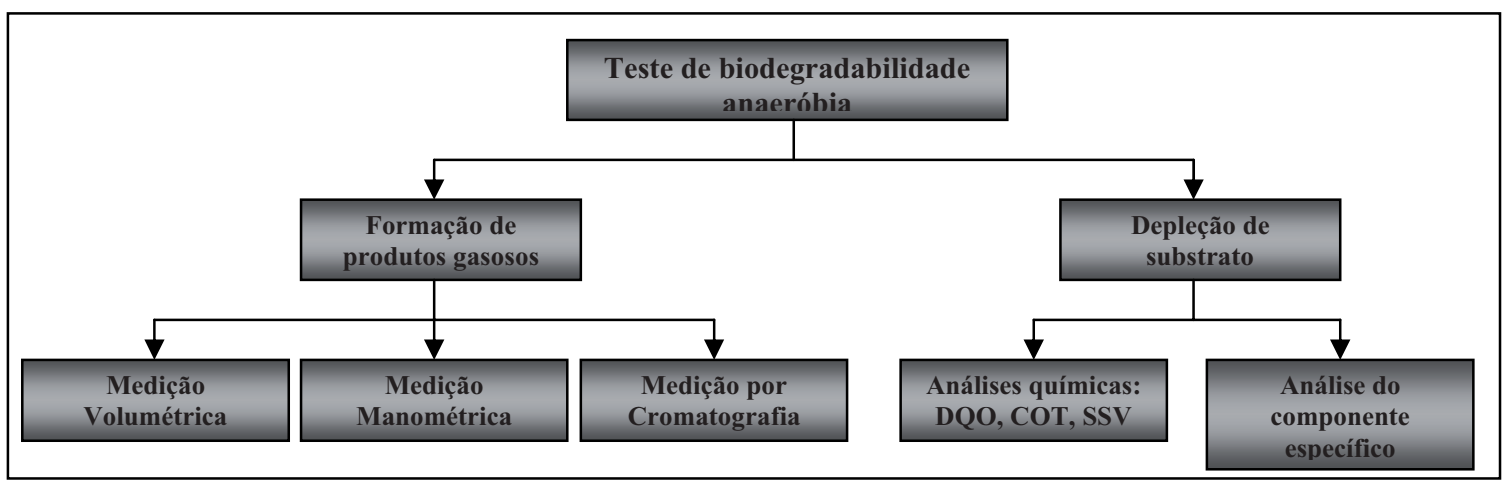

Figura I - Descrição dos tipos de teste de biodegradabilidade anaeróbia 
do lodo de um sistema similar ao que se pretende usar em escala real caso o teste indique tratamento biológico.

Outro importante fator em relação ao inóculo é a quantidade a ser adicionada. $\mathrm{O}$ emprego de pequena quantidade de inóculo (alta relação $\mathrm{A} / \mathrm{M}$ ) pode levar à sobrecarga do processo resultando em acidificação devido ao acúmulo de AGV. Além disso, o tempo para finalização do teste será diretamente proporcional à relação $\mathrm{A} / \mathrm{M}$. Por outro lado, o emprego de grandes quantidades de inóculo pode levar a uma superestimação da produção de metano devido aos fenômenos de decaimento e lise dos microrganismos envolvidos (Lopes et al, 2004, Neves et al, 2004, Owen et al, 1979, e Raposo et al, 2006).

Para desenvolvimento do inóculo também é necessário a disponibilidade de macro (N, P, Ca, Fe) e micronutrientes (minerais e vitaminas). Speece (1996) enfatiza a importância da presença balanceada dos nutrientes necessários, sendo que a restrição ou falta de apenas um deles pode levar a redução da taxa de metanogênese, acúmulo de AGV e consumo de alcalinidade. Segundo Takashima et al (1989), nitrogênio, fósforo, enxofre, cálcio, magnésio, ferro, cobalto e níquel são essenciais para manter altas taxas de utilização de acetato. Diversas enzimas contendo íons de níquel e cobalto, tais como co-enzimas $\mathrm{F}_{420}$, são envolvidas na metanogênese, sendo então necessário a presença de tais para estimular a metanogênese.

$\mathrm{O}$ pH é outro fator que apresenta grande influencia no processo anaeróbio. $\mathrm{O} \mathrm{pH}$ influencia a atividade das enzimas hidrolíticas e dos microrganismos de todo o consórcio anaeróbio, principalmente dos microrganismos que têm baixa taxa de crescimento, como os metanogênicos. O processo de digestão anaeróbia ocorre no intervalo de $\mathrm{pH}$ de 6 a 8,3, sendo que valores de $\mathrm{pH}$ fora do intervalo ótimo podem inibir o processo de degradação, levando a subestimação da biodegradabilidade (Angelidaky et al, 2004). Neste caso é necessário, para o desenvolvimento do processos de degradação, o ajuste do $\mathrm{pH}$, com adição de agentes que proporcionem tamponamento do sistema na faixa ótima de $\mathrm{pH}$.

A temperatura afeta a manutenção e crescimento dos microrganismos, bem como na atividade metabólica dos mesmos. Segundo Hashinomoto et al
(1981), temperaturas entre 30 e $60^{\circ} \mathrm{C}$ não afetam a taxa de produção acumulada de metano, enquanto que temperaturas fora deste limite levam à uma menor produção de metano. No entanto, a maioria dos estudos de biodegradabilidade anaeróbia é realizada na temperatura de $30 \mathrm{ou}$ $35^{\circ} \mathrm{C}$, e nestes casos, o resultado obtido indicará muito provavelmente a biodegradabilidade potencial, haja vista que a maioria dos sistemas de tratamento serão operados com temperaturas bem menores $\left(20\right.$ a $\left.25^{\circ} \mathrm{C}\right)$.

$\mathrm{Na}$ literatura são apresentados poucos trabalhos de biodegradabilidade de lixiviados de aterros sanitários. Santos et al (2004) avaliaram a biodegradabilidade aeróbia e anaeróbia de lixiviados, sendo o teste de biodegradabilidade anaeróbia realizado segundo metodologia proposta por Field et al (1988). Os resultados de Santos et al (2004) mostram que a biodegradabilidade aeróbia do lixiviado (remoção de $65 \%$ de DQO sem adição de inóculo e de $87 \%$ com adição de inoculo) foi superior a biodegradabilidade anaeróbia (60\%). Berrueta et al (1996) também avaliou a biodegradabilidade anaeróbia de lixiviado, só que de aterro antigo, e obteve valores de biodegradabilidade da ordem de 40 a $50 \%$.

Em outro estudo com lixiviados de aterro, Jette et al. (1998) mostraram que 33\% da matéria orgânica dissolvida apresentava alto peso molecular ( $1.000 \mathrm{Da})$ e tinham baixa biodegradabilidade. Da mesma forma, Gourdon et al (1989) determinaram a distribuição de peso molecular das fraçóes de lixiviados de aterro sanitário que recebiam resíduo industrial, antes e depois do tratamento aeróbio e anaeróbio, para avaliar a biodegradabilidade aeróbia e anaeróbia. Os autores observaram que a maior parte dos compostos orgânicos apresentava baixo peso molecular (<500 Da). Tanto a fração de baixo peso molecular quanto a fração de alto peso molecular apresentaram maior biodegradabilidade aeróbia, sendo que os compostos refratários após tratamento aeróbio e anaeróbio, avaliados por HPLC foram os mesmos.

Com base na revisão de literatura percebe-se a importância de se estabelecer e padronizar as condiçōes operacionais e ambientais para o desenvolvimento dos testes de biodegradabilidade. Sendo assim os objetivos deste artigo foram investigar as condiçóes de incubação mais favoráveis ao desenvol- vimento do teste baseado na medição da produção acumulada de metano, aplicado para determinação da biodegradabilidade anaeróbia de lixiviados de aterro sanitário.

\section{METODOLOGIA}

\section{Amostragem}

O lixiviado utilizado para a realização dos experimentos proveio do Aterro Sanitário da Central de Tratamento de Resíduos Sólidos (CTRS) da cidade de Belo Horizonte - MG - Brasil, em operação desde 1975 . O aterro ocupa uma área de 133 hectares e se localiza na região Noroeste da capital mineira, possuindo células de aterramento com diferentes idades e características. O lixiviado foi coletado no reservatório que recebe contribuiçôes das células AC01, AC03 e AC05, que estão em operação a 20, 10 e 6 anos, respectivamente.

O lodo empregado como inóculo foi coletado de reator UASB da ETEExperimental (UFMG/COPASA - Belo Horizonte - MG). Todas as coletas de lodo foram realizadas a uma mesma altura (0,7 $\mathrm{m}$ da extremidade inferior) sob mesma condição operacional do reator UASB. O reator UASB opera com vazão média afluente $2,88 \mathrm{~m}^{3} / \mathrm{h}$, carga orgânica volumétrica $1,74 \mathrm{KgDBO} / \mathrm{m}^{3}$ e tempo de detenção hidráulica no reator UASB 6,9 horas.

\section{Caracterização físico- química do líxiviado e do lodo}

Devido à grande variabilidade de composição do lixiviado, as amostras selecionadas foram previamente caracterizadas. Para a caracterização dos lixiviados foram utilizados os seguintes parâmetros físico-químicos: DQO, DBO, pH, alcalinidade, série sólidos, nitrogênio total e amoniacal. O lodo usado como inóculo foi caracterizado quanto a concentração de sólidos suspensos. Todas as análises foram realizadas em conformidade com as recomendaçōes do Standard Methods for the Examination of Water and Wastewater (APHA, 1992).

\section{Avaliação da biodegradabilidade anaeróbia}

A biodegradabilidade anaeróbia foi avaliada adaptando-se o teste de 
biochemical methane potential (BMP) proposto por Owen et al. (1979). Alíquotas de lixiviado foram inoculadas com lodo e solução de nutriente preparada de acordo com o procedimento recomendado para os ensaios de determinação da atividade metanogênica específica (Souza et al, 2005). Foram utilizados frascos de antibióticos de $250 \mathrm{ml}$ em atmosfera de nitrogênio e dióxido de carbono (70:30 v/v). Após a adição das amostras, os frascos eram fechados, lacrados e incubados por 30 dias a $30^{\circ} \mathrm{C}$ sob agitação contínua de $210 \mathrm{rpm}$ em uma incubadora shaker. Para avaliar a produção de metano devido ao decaimento endógeno, em alguns frascos o lixiviado foi substituído por água destilada (frascos "branco"). Para se avaliar a atividade da biomassa, substituiu-se, em alguns frascos, o lixiviado por uma solução de glicose com concentração equivalente a concentração original do lixiviado (frascos "controle”). A produção de biogás foi medida empregando seringa de vidro esmerilhada e a quantificação de metano foi feita por cromatografia gasosa usando cromatógrafo Perkin-Elmer Austosystem XL, equipado com detector de condutividade térmica, e utilizando-se uma coluna empacotada com material tipo "molecular sieve". Utilizou-se hélio como gás de arraste e as temperaturas do forno e do detector foram de $60 \mathrm{e}$ $150^{\circ} \mathrm{C}$ respectivamente.

Para calcular a fração do lixiviado biodegradável anaerobiamente, converteu-se o volume acumulado de metano em massa de DQO (a $30{ }^{\circ} \mathrm{C} 1 \mathrm{~g}$ de DQO corresponde a $393 \mathrm{ml}$ de $\mathrm{CH}_{4}$ ) e dividiu-se esse resultado pela massa de DQO incubada. A DQO inicial foi deduzida em $10 \%$ de forma a levar em conta a fração de substrato utilizada para síntese celular $(\mathrm{Y}=0,10)$, conforme valores de coeficiente de produção celular comumente utilizados para sistemas anaeróbios (Aquino e Chernicharo, 2005). A biodegradabilidade foi determinada medindo-se a produção de biogás no $5^{\circ}, 10^{\circ}, 20^{\circ}$ e $30^{\circ}$ dias de incubação.

As seguintes condições de incubação foram avaliadas: relação (A/M), aclimatação da biomassa e toxicidade devido a alta concentração de amônia.

Para avaliar a relação $\mathrm{A} / \mathrm{M}$ mais favorável foram realizados testes empregando valores de 0,34, 0,45 e $0,7 \mathrm{mg}$ de $\mathrm{DQO} / \mathrm{mg}$ de SSV. A quantidade de lixiviado e nutrientes foi a mesma para todos os frascos, e a relação $\mathrm{A} / \mathrm{M}$ foi mudada variando-se somente a quantidade de inóculo empregada.

A aclimatação do lodo foi realizada de duas maneiras. Na primeira forma partiu se do pressuposto de que durante o teste de biodegradabilidade o lodo passa por um processo natural de aclimatação, com isso o processo de aclimatação consistiu em utilizar lodo de ensaios de biodegradabilidade já concluídos. $\mathrm{Na}$ segunda forma, o lodo foi aclimatizado durante 21 dias recebendo carga crescente de lixiviado e decrescente de solução de nutrientes. Sendo assim foram realizados ensaios empregando-se o lodo dos frascos de ensaios que já haviam sido concluídos e ensaios empregando-se lodo submetido ao processo de aclimatação por 21 dias conforme descrito acima.

A toxicidade devido a alta concentração de amônia foi avaliada comparando a biodegradabilidade do lixiviado in natura e do lixiviado submetido ao processo de remoção de amônia por air stripping. Para tanto o lixiviado teve $\mathrm{pH}$ ajustado para 9,5 empregando $\mathrm{NaOH}$ e depois submetido à aeração por $12 \mathrm{~h}$. Após as $12 \mathrm{~h}$ de aeração o $\mathrm{pH}$ foi ajustado a 7 com $\mathrm{H}_{3} \mathrm{PO}_{4}$.

\section{RESULTADOS E DISCUSSÕES}

\section{Caracterizacão físico- química do líxiviado e do lodo}

Nas Tabelas 1 e 2 são apresentados, respectivamente, os resultados da caracterização do lixiviado e do lodo utilizados nos testes de biodegradabilidade.

Os baixos valores de DBO/DQO indicam baixa biodegradabilidade aeróbia do lixiviado, confirmando que o aterro se encontra em um estado avançado de estabilização, ou seja os lixiviados se apresentam em alta condição de oxidação. Observa-se ainda uma elevada concentração de íons amônia e baixo teor de sólidos. Os valores de concentração de nitrogênio encontrados ultrapassam o que é encontrado na literatura para lixiviados de células nestas faixas de idade. A concentração de fósforo é baixa, mas não indica ocorrência de deficiência nutricional em relação a fósforo. Em relação a presença de metais pesados, observase a presença significativa somente de ferro, no entanto, a presença de ferro a esse nível não atribui toxicidade aos microrganismo.

\section{Avaliação da relação $\mathrm{A} / \mathrm{M}$}

$\mathrm{Na}$ Figura 2a e 2b são apresentados os volumes acuulados de metano e os valores de biodegradabilidade do lixiviado após 10 e 30 dias, em função da relação $\mathrm{A} / \mathrm{M}$ adotada.

Observa-se que uma relação $\mathrm{A} / \mathrm{M}$ equivalente a $0,45 \mathrm{mg}$ de $\mathrm{DQO} / \mathrm{mg}$ de SSV resultou em maior valor de biodegradabilidade. A baixa produção acumulada de metano e, conseqüentemente, a baixa biodegradabilidade observada nos ensaios empregando relação $\mathrm{A} / \mathrm{M}$ equivalente a 0,7 mg de $\mathrm{DQO} / \mathrm{mg}$ de SSV provavelmente se deve a escassez relativa de microrganismo, enquanto que para os ensaios empregando relação A/M equivalente a $0,34 \mathrm{mg}$ de $\mathrm{DQO} / \mathrm{mg}$ de SSV os baixos valores provavelmente se deve disponibilidade excessiva de microrganismo em relação a quantidade de alimento disponível resultando na sobrecarga de matéria orgânica.

Observa-se também a diferença significativa entre o volume de metano produzido após 10 e 20 dias. O baixo volume de metano produzido após 10 dias em relação ao produzido em 30 dias provavelmente se deve a baixa concentração de matéria orgânica rapidamente biodegradável, ou seja, o lixiviado é constituído de matéria orgânica biodegradável, mas que demanda um maior tempo de incubação para ser biodegradada.

\section{Influência da aclimatação do lodo}

$\mathrm{Na}$ Figura 3a e 3b são apresentados os volumes de metano produzidos e a biodegradabilidade do lixiviado obtidos empregando-se tanto lodo não aclimatizado (in natura) quanto lodo aclimatizado sob diferentes condiçôes.

Observa-se que os ensaios empregando lodo aclimatizado apresentaram menor remoção de matéria orgânica. Durante a aclimatação do lodo pode haver uma seleção dos microrganismos que são aptos à degradação da matéria orgânica do lixiviado bem como resistentes a toxicidade presente, ou seja, é possível que durante a aclimatação haja uma redução do número total de microrganismos. Ferreira et al (2006) 
Tabela I - Caracterização do lixiviado

\begin{tabular}{cccc}
\hline Parâmetros & Unidade & Valor médio & Desvio padrão \\
\hline DQO & $\mathrm{mg} / \mathrm{L}$ & 2576 & 166,9 \\
$\mathrm{DBO}_{5}$ & $\mathrm{mg} / \mathrm{L}$ & 113 & 37,7 \\
$\mathrm{DBO} / \mathrm{DQO}$ & $\mathrm{mg} / \mathrm{L}$ & 0,05 & 0,02 \\
$\mathrm{pH}$ & - & 8,2 & 0,1 \\
Nitrogênio Total & $\mathrm{mg} / \mathrm{L}$ & 1201 & 95,9 \\
Nitrogênio amoniacal & $\mathrm{mg} / \mathrm{L}$ & 1079 & 57,8 \\
Alcalinidade & $\mathrm{mg} / \mathrm{L}$ & 6536 & 312,9 \\
Fósforo & $\mathrm{mg} / \mathrm{L}$ & 10 & 0,5 \\
SST & $\mathrm{mg} / \mathrm{L}$ & 52 & 14,2 \\
SSF & $\mathrm{mg} / \mathrm{L}$ & 16 & 19,4 \\
SSV & $\mathrm{mg} / \mathrm{L}$ & 36 & 16,5 \\
Ferro & $\mathrm{mg} / \mathrm{L}$ & 9,15 & 1,3 \\
Chumbo & $\mathrm{mg} / \mathrm{L}$ & 0,22 & 0,02 \\
Cádmio & $\mathrm{mg} / \mathrm{L}$ & $<0,02$ & - \\
Zinco & $\mathrm{mg} / \mathrm{L}$ & 0,25 & 0,10 \\
Cromo & $\mathrm{mg} / \mathrm{L}$ & 0,25 & 0,05 \\
\hline
\end{tabular}

Tabela 2 - Caracterização dos lodos anaeróbio utilizados como inóculo

\begin{tabular}{cccc}
\hline Parâmetros & Unidade & Valor médio & Desvio padrão \\
\hline SST & $\mathrm{g} / \mathrm{L}$ & 20,3 & 4,9 \\
$\mathrm{SSF}$ & $\mathrm{g} / \mathrm{L}$ & 7.8 & 6,6 \\
$\mathrm{SSV}$ & $\mathrm{g} / \mathrm{L}$ & 12,5 & 1,9 \\
\hline
\end{tabular}
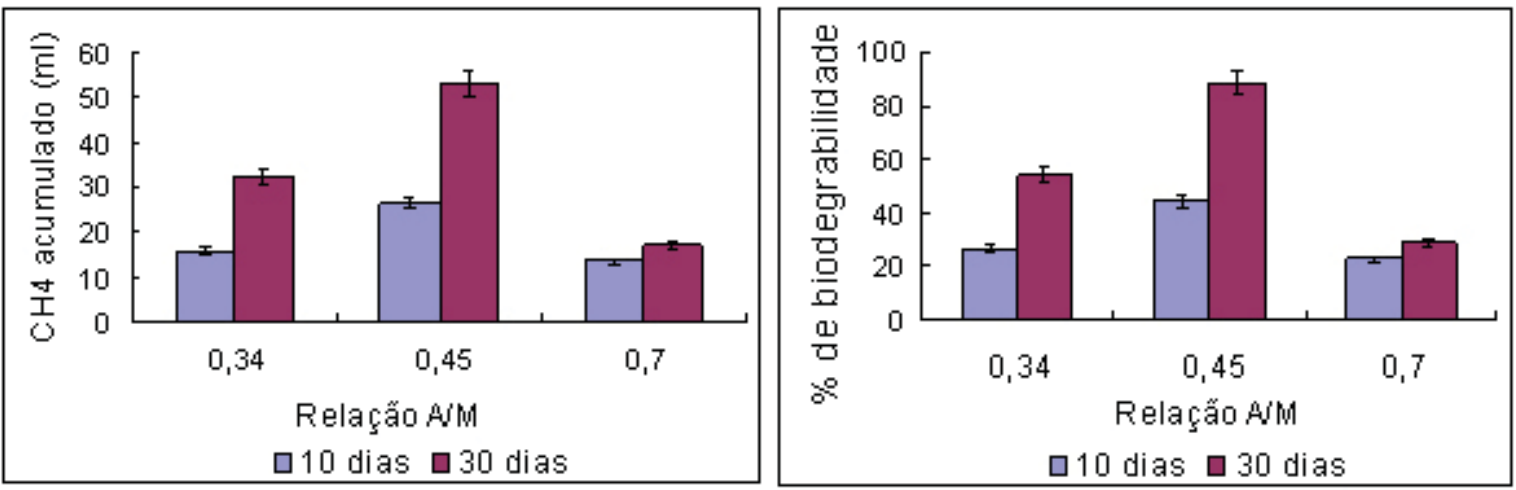

Figura 2 - Volume de metano acumulado (a) e biodegradabilidade(b) em função da relação $A / M$ adotada 


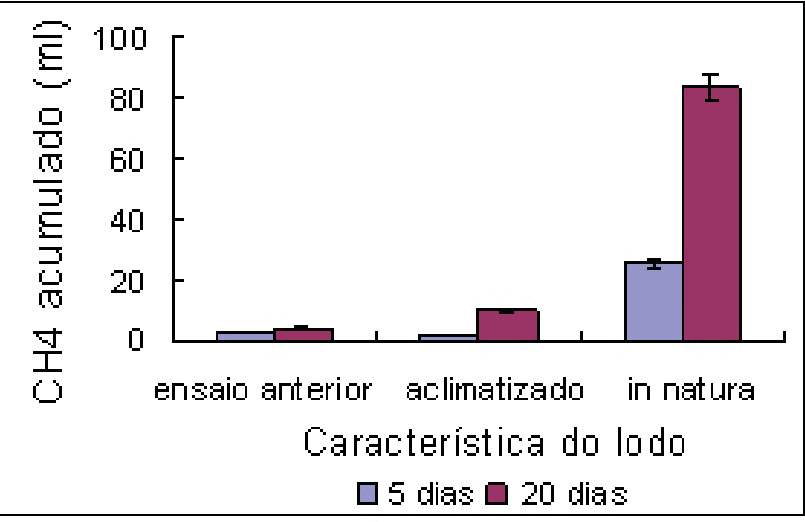

(a)

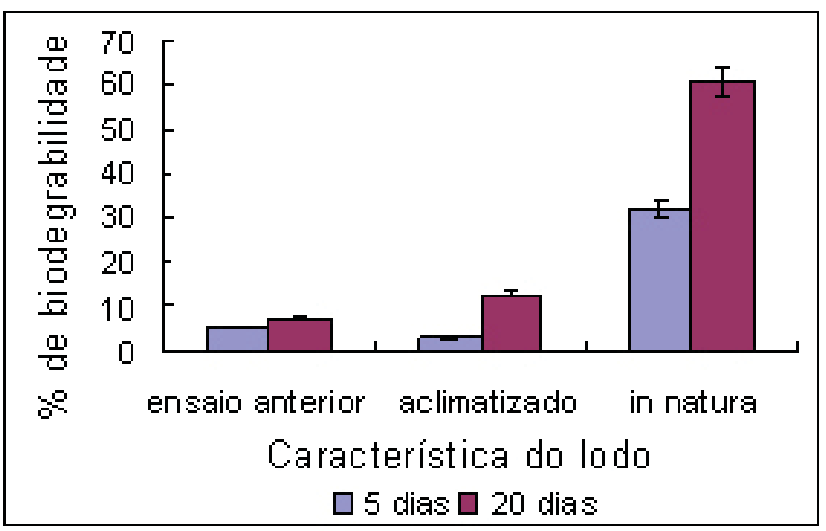

(b)

Figura 3 - Volume de metano produzido (a) e biodegradabilidade (b) em função da característica do lodo

empregando o mesmo lixiviado, realizaram ensaios de DQO inerte sob condições anaeróbias empregando lodo in natura e lodo aclimatizado, sob mesmas condições empregadas neste estudo e observaram, através das curvas de decaimento obtidas, que ambos os lodos alcançaram o mesmo grau de remoção de matéria orgânica, mas com tempos de incubação diferentes. Os dados de Ferreira et al (2006) indicam que o lodo in natura apresentou maior atividade no início do teste, sofrendo decaimento e lise na seqüência, ao passo que o lodo submetido ao processo de aclimatação não sofreu decaimento e lise, mas apresentou menor atividade quando comparado ao lodo in natura. Tais resultados indicam que no início do ensaio empregando lodo in natura há um maior número de microrganismos que, mesmo não sendo resistentes à toxicidade, são capazes de degradar a matéria orgânica presente. Com o prosseguimento do teste tais microrganismos acabam sendo eliminados devido à maior exposição aos compostos tóxicos.

Os resultados do presente estudo indicam que não há necessidade de submeter o lodo ao processo de aclimatação, pois os microrganismos do inóculo são capazes de degradar a matéria orgânica biodegradável presente no lixiviado. Acredita-se que a fração biodegradável do lixiviado seja semelhante à matéria orgânica do esgoto, o qual era o substrato anterior do lodo empregado, fração esta constituída de proteínas, carboidratos e lipídeos, e a lise provavelmente ocorre devido a toxicidade dos compostos refratários e/ou alta concentração de amônia. Segundo Amaral et al (2006), que empregaram o mesmo lixiviado para avaliação da fração inerte presente, cerca de $60 \%$ da matéria orgânica é constituída de proteínas, lipídeos e carboidratos e os demais $40 \%$ correspondem a compostos não identificados que provavelmente apresentam natureza refratária, conforme indicado pelo alto teor de DQO inerte determinado experimentalmente.

\section{Efeito da toxicidade da amônia na biodegradação anaeróbia}

$\mathrm{Na}$ Tabela 3 são apresentados os resultados da caracterização do lixiviado in natura e do lixiviado submetido à remoção de amônia por air stripping.

Observa-se que o processo de air stripping removeu cerca de $80 \%$ da amônia presente e promoveu uma pequena elevação da DQO, o que pode estar relacionado à solubilização de compostos com o aumento do pH. Esta hipótese é reforçada pela redução de concentração de SSV. A redução da DBO pode ser atribuída pela volatilização dos compostos biodegradáveis voláteis.
$\mathrm{Na}$ Figura 4a e 4b são apresentados os volume de metano produzido e a biodegradabilidade do lixiviado obtidos empregando lixiviado in natura e lixiviado submetido ao air stripping.

Observa-se que embora o lixiviado apresente alta concentração de amônia, não há indícios de toxicidade aos microrganismos anaeróbios inerente à amônia. Embora a faixa de inibição mais aceita é de 100 a $200 \mathrm{mg} / \mathrm{L}$, diferentes autores estabelecem diferentes limites de inibição. Calli et al (2005) observaram que nenhum efeito inibitório foi causado devido a concentração de amônia para valores de amônia livre até $161 \pm 12 \mathrm{mg} / \mathrm{L}$, Koster et al (1984) observaram inibição com concentração de amônia livre superior a $700 \mathrm{mg} / \mathrm{L}$ e Hansen et al, 1998, a inibição foi observada somente para concentraçôes superiores a $1.100 \mathrm{mg} / \mathrm{L}$ de amônia livre.

Considerando o valor de $\mathrm{pH}$ do lixiviado $(8,0)$ e a equação de Ostergaard que relacionam amônia total e amônia livre em função da temperatura 


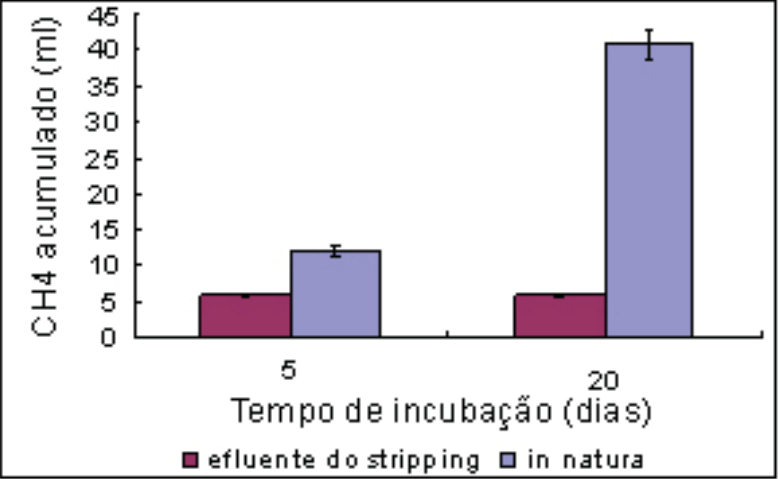

(a)

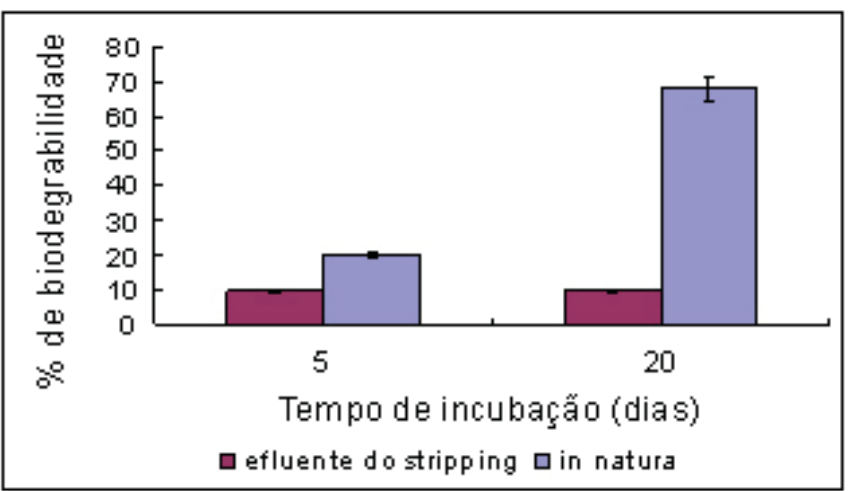

(b)

Figura 4 - (a) Volume de CH4 produzido, (b) biodegradabilidade em função da característica do lodo

e pH, calcula-se que a concentração de amônia livre dissolvida seja de aproximadamente $130 \mathrm{mg} / \mathrm{L}$, ou seja, a concentração de amônia livre está dentro da faixa em que não foram observados efeitos inibitórios encontrados por Calli et al (2005), Koster et al (1984) e Hansen et al, 1998.

Os baixos valores de biodegradabilidade obtidos para o lixiviado submetido ao processo de air stripping provavelmente se devem a elevado teor de oxigênio, o qual é letal aos microrganismos anaeróbios, e também a produção heterotrófica de microrganismos aeróbios durante a aeração que podem ser responsável pela redução da DBO, ou seja, redução da fração de matéria orgânica biodegradável. Bonmatí et al (2003) avaliou o emprego do processo de air stripping como pré e pós-tratamento de tratamento anaeróbio e observou que o processo de air stripping como pré-tratamento apresentou menor produção de metano. Segundo o autor embora há uma significante remoção de amônia durante $\mathrm{o}$ air stripping, a elevação do $\mathrm{pH}$ não conduz a redução da amônia livre e conseqüentemente não há redução do seu efeito inibitório.

\section{Quantificação da Biodegradábilidade anaeróbia}

Avaliada as condições operacionais, estabeleceu-se a realização do teste de BMP empregando relação A/M de 0,45 e lodo in natura. Na Figura 5 é apresentado o aumento da biodegradabilidade do lixiviado com o tempo de incubação.
Considerando-se que o emprego do lodo após incubação de 30 dias apresentou baixa atividade, e tendo em vista que a DQO inerte do lixiviado foi determinada em cerca de $42 \%$ da DQO total (Amaral et al, 2006), estima-se que um tempo de incubação de 20 dias seja suficiente para fornecer o valor de biodegradabilidade do lixiviado. Um tempo de incubação superior a 20 dias poderia resultar na super-estimação da biodegradabilidade do lixiviado devido à produção adicional de metano resultante do decaimento endógeno e lise celular como parece ter ocorrido (Figura 5). A correção da produção de metano empregando o frasco denominado branco não é suficiente para eliminar esta super-estimação, pois o valor da produção de metano residual é determinada empregando água destilada em substituição ao lixiviado, ou seja, condição restrita de matéria orgânica, enquanto que a 30 dias o lixiviado apresenta certa restrição de matéria orgânica biodegradável e toxicidade, ou seja, apresenta mais condiçóes que favorecem a lise celular. Neste sentido a produção de metano devido ao decaimento endógeno e lise celular no frasco alimentado com lixiviado é mais favorável do que no frasco alimentado com água. Os valores da biodegradabilidade anaeróbia do lixiviado encontrados são semelhantes aos encontrados por Santos et al (2004) para o lixiviado do aterro de Muribeca - PE.

Os valores de biodegradabilidade observados sugerem que lixiviado com características semelhantes a este estudado, considerando ainda os dados de concentração de DQO inerte apresentados por Amaral et al (2006), apresentam boa eficiência de remoção da matéria orgânica biodegradável por processos anaeróbios. No entanto, a baixa biodegradabilidade anaeróbia em relação à concentração de matéria orgânica total, associada aos baixos valores de relação DBO/DQO (Tabelas 1 e 3) sugerem que para o tratamento deste lixiviado é necessário a associação de

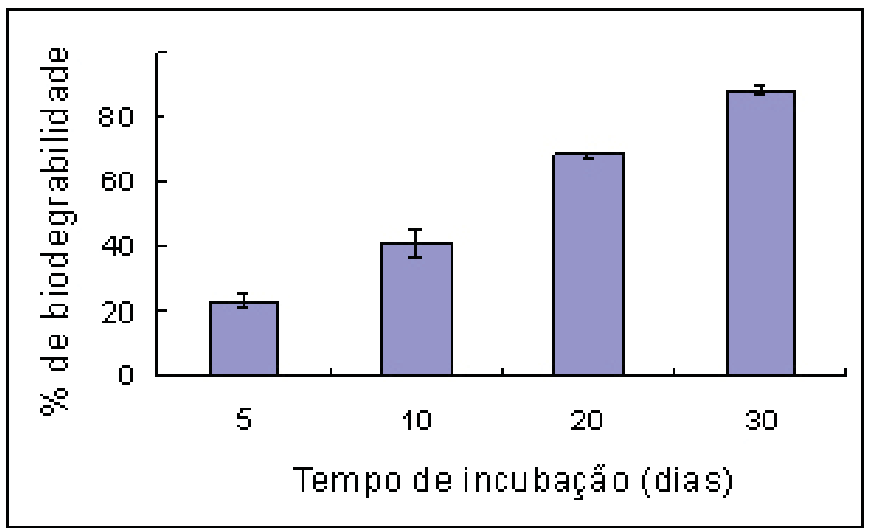

Figura 5 - Biodegradabilidade anaeróbia do lixiviado 
tratamento físico-químico como etapa de pré ou pós-tratamento para então conseguir enquadramento dentro do que é exigido pela legislação.

\section{CONCLUSÕES}

A investigação das melhores condições ambientais e operacionais para realização do teste de biodegradabilidade anaeróbia de lixiviados de aterro indicou que a relação $\mathrm{A} / \mathrm{M}$ equivalente a 0,45 apresentou-se como a mais favorável à realização do teste. Além disso o lodo empregado apresentou boa capacidade de adaptação ao lixiviado, não demandando aclimatação, e embora o lixiviado apresentou alta concentração de amônia, não há indícios de toxicidade aos microrganismos anaeróbios. O lixiviado em questão apresentou biodegradabilidade anaeróbia de aproximadamente $20 \%$ a 5 dias, $40 \%$ a 10 dias, $67 \%$ a 20 dias e $88 \%$ a 30 dias, ressaltando que o valor a 30 dias possa estar superestimado. Estes valores são baixos quando se leva em consideração o valor da DQO total, mas são altos consideran-do a fração inerte que compóe o lixiviado. Dessa forma, para o tratamento deste lixiviado, é necessário a asso ciação de tratamento físico-químico como etapa de pré ou pós-tratamento.

\section{REFERÊNCIAS}

AMARAL, M.C.S. et al. Determinação da Fração da DQO Solúvel de Lixiviados de Aterro Sanitário Inerte à Processos Aeróbio e Anaeróbio: Parte II - Comparação de Diferentes Metodologias. Revista Engenharia Sanitária, submetido, 2006a.

AMARAL, M.C.S. et al. Determinação da distribuição de pesos moleculares da matéria orgânica presente em lixiviados de aterro sanitário. Parte I: análise de confiabilidade da técnica de ultrafiltração. Revista Engenharia Sanitária, submetido, 2006b.

ANGELIDAKI, I., WENDY, S. Assessment of the anaerobic biodegradability of macropollutants. Reviews in Environmental Science and Technology, v.3, p.117-129. 2004.

APHA. Standard Methods for the Examination of Water and Wastewater. 21 th Edition. American Public Health Association, Washington, DC. 2005.

AQUINO, S.F e CHERNICHARO, C.A.L. Acúmulo de ácidos graxos voláteis $(A G V s) \mathrm{em}$ reatores anaeróbios sob estresse: causas e estratégias de controle. Engenharia Sanitária e Ambiental, v. 10, n. 2, p. 152-161. 2005.

BARKER, D.J.; STUCKEY,D.C. A review of soluble microbial products (SMP) in wastewater treatment systems. Water Research, v. 33, n. 14, p. 3063-3082, 1999.
BERRUETA, J.; GUTÉRREZ, A.; FUEYO, G. Anaerobic treatment of leachates in pilot-scale UASB: strategy of start-up. Journal of Chemical Technology and Biotechnology. v. 67, n. 3, p. 302-314, 1996

BONMATÍ, A., FLOTATS, X. (2003). Air stripping of ammonia from pig slurry: characterization and feasibility as pre or post-treatment to mesophilic anaerobic digestion. Waste Management, v.23, p.261-272.

CALLI, B.et al. Methanogenic diversity in anaerobic bioreactors under extremely high ammonia levels. Enzyme and Microbial Technology, v. 37, p. 448-445. 2005

DOLFING, J., BLOEMAN, W.G.B.M. Activity measurements as tool to characterize the microbial composition of methanogenic environments. J. Microbiol. Methods, v.4, p.1-12. 1985.

FERREIRA, C.A.F. et al. Determinação da Fração da DQO Solúvel de Lixiviados de Aterro Sanitário Inerte à Processos Aeróbio e Anaeróbio: Parte I Influência das Condiçóes de Teste. Revista Engenharia Sanitária, submetido.

FIELD, J.; SIERRA, R.; LETTING, G. Ensayos anaerobios. IN: 40 SEMINARIO DE DEPURACIÓN DE AGUAS RESIDUALES SPAIN: VALLADOLID. 1998.

GUWY, A.J. Equipament used for testing anaerobic biodegradability and activity. Reviews in Environmental Science and Technology, v.3, p.131-139. 2004.

HASHIMOTO A.G. Effect of inoculum/substrate ratio on methane yield and production rate from straw. Biol. Wastes v. 28, n.4, p.274-255. 1989.

JETTE, B. C. et al. Characterization of the dissolved organic carbon in landfill leachatepolluted grooundwater. Wat. Res. V. 32, n.1, p 125-135. 1998.

LOPES, W.S., LEITE, V.D., PRASAD,S. Influence of inoculum on performance of anaerobic reactors for testing municipal solid waste. Bioresour. Techn., v. 94, p. 261-266. 2004.

MULLER, W.R., FROMMERT, I., JORG, R. Standardized methods for anaerobic biodegradability testing. Reviews in Environmental Science and Technology, v.3, p.141-158. 2004.

NEVES, L., OLIVEIRA, R., ALVES, M.M. Influence of inoculum activity on the biomethanization of a kitchen waste under different wastelinoculum ratios. Process Biochem., v. 39, p. 2019-2024. 2004.

OWEN, W.F., STUCKEY D.C. Bioassay for Monitoring Biochemical Methane Potential and Anaerobic Toxicity. Water Research n. 13, p. 485-492, 1979.

RAPOSO, F. et al. Influence of inoculum to substrate ratio on the biochemical methane potential of maize in batch tests. Process Biochemistry, v.41, p. 1444-1450. 2006.

ROZZI, A., REMIGI, E. Methods of assessing microbial activity and inhibition under anaerobic conditions: a literature review. Reviews in Environmental Science and Technology, v.3, p.93-115. 2004.

SANTOS, A.F.M.S., KATO, M.T., FLORENCIO,L. Estudo comparativo entre a biodegradabiliade aeróbia e anaeróbia de chorume de aterro controlado. In: XI SILUBESA, Rio Grande do Norte - Brasil. 2004.
SOUZA, C. L. et al. Determinação da biodegradabilidade anaeróbia e aeróbia da escuma produzida em reatores UASB tratando esgotos domésticos. Anais do XV Simpósio Nacional de Bioprocessos, Recife, PE, Brasil. 2005.

SPEECE, R. E. Anaerobic biotechnology for industrial wastewaters. Archaea Press. 1966.

TAKASHIMA, M., SPEECE, R.E. Mineral nutrient requeriments for high-rate methane fermentation of acetate at low SRT. Res. J. Wat. Poll. Contr. Fed., v. 61, n. 11-12, p. $1645-1650$.

\section{Endereço para correspondência:}

Míriam Cristina Santos Amaral Universidade Federal de Minas Gerais Departamento de Engenharia Sanitária e Ambiental Av. do Contorno, 842 - $7^{\circ}$ andar 301 I 0-060 Belo Horizonte - MG - Brasil

Tel: (3 I)3409- 1007

Fax: (3 I)3409-I 879

E-mail:miriam@desa.ufmg.br 